\title{
The multiple degrees of freedom magnet-track relationship in Maglev train
}

\author{
Jiaolong Wen ${ }^{1, a}$, Yaozong Liu $^{1, b}$ and Dingxiao $\mathrm{Zhu}^{1, \mathrm{c}}$ \\ ${ }^{1}$ National University of Defense Technology, Changsha 410072, China. \\ a137856679@qq.com, byaozong.liu@163.com, c xiaoxiao199064@126.com
}

Keywords: Maglev train, magnetic-track relationship, finite element, suspension electromagnetic force.

\begin{abstract}
The research of magnet-track relationship is the foundation and key point in maglev system dynamics. Due to the ups and downs, traverse, yaw, pitch and roll of the suspension electromagnet will certainly happen when maglev train moves, so establish three-dimensional numerical model and calculate the suspension electromagnetic force by using Ansoft software. The simulation result shows that the influence of yaw angle on the suspension electromagnetic force is not large, but other four degrees of freedom position changes of the electromagnet will have a great influence on the force. In particular, it creates a patent coupling to the suspension electromagnetic force, when traverse and pitch movement or pitch and roll movement of the suspension electromagnet exist.
\end{abstract}

\section{Introduction}

The key point of different between maglev train and wheel rail train is that the magnet-track relationship replace the relationship between wheel and rail. Magnet-track relationship is the relationship between the suspension electromagnetic force, air gap and control current. The research of magnet-track relationship is the foundation and key point in maglev system dynamics. Due to the ups and downs, traverse, yaw, pitch and roll of suspension electromagnet will certainly happen when maglev train moves, the research of magnet -track relationship is needed.

There are many scholars research on magnet-track relationship of maglev train. W. Brzezina and J. Langerholc firstly carried out the complex magnetic-train relationship [1]. They obtained calculation formula of electromagnetic force and rolling force by using conformal transformation, which means simplifying two-dimensional four angles problem of rectangle magnetic pole pair as two angles. Xie Yunde and Chang Wensen proposed a new suspension electromagnetic force calculation formula based on the conformal transformation and the infinite series theories [2]. The formula demonstrated that the large roll angle took a prominent influence on suspension electromagnetic force and formed unstable positive feedback. Luo Fang and Zhang Kunlun achieved the numerical solution of electromagnetic lift force, lateral force and roll torque by analyzing the 2D distribution of electromagnetic field [3, 4]. Liu Shaoke researched the suspension electromagnetic force characteristics under suspension electromagnet rolling based on finite element simulation [5,6]. Ni Hongyan researched relationship between the suspension electromagnetic force and current changes loading in the suspension electromagnet coil [7]. Zhang Kun proposed the formula of suspension electromagnetic force calculation when the suspension electromagnet was pitching [8]. The research above was lack of the analysis of the suspension electromagnetic force characteristics when the electromagnet moves on five degrees of freedom. This paper, on the basis of the study above, established three-dimensional numerical model and calculated the suspension electromagnetic force by using Ansoft software. Meanwhile the paper approached the influence of five degrees of freedom of the position change of electromagnet to suspension electromagnetic force, and this will help to build a more accurate model of the suspension electromagnetic force, thereby providing magnet-track relationship model more tally with actual for maglev train control technology research and kinetic studies. 


\section{Analytical method}

The diagram of the structure of the magnet-track relationship is shown in Fig. 1. The electromagnet pole and track pole alignment is no longer when the electromagnet is traverse, yaw, pitch and roll. This paper, on the basis of maglev train researched by National University of Defense Technology, simplified three-dimensional numerical model according to the actual size and calculated the suspension electromagnetic force by using Ansoft software. Concrete model analysis steps are as follows.

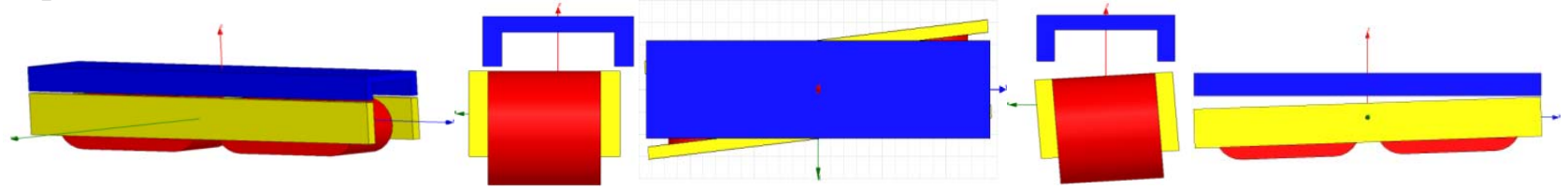

Fig. 1 Suspension electromagnet three-dimensional finite element model

Finite element analysis model is established. According to the magnet size relations, The electromagnet parameters are shown in Table 1.

Table 1 Suspension electromagnet parameters

\begin{tabular}{cc}
\hline $\begin{array}{c}\text { Suspension electromagnet } \\
\text { parameters }\end{array}$ & $\begin{array}{c}\text { Numerical } \\
\text { value }\end{array}$ \\
\hline The coil number of turns (N) & 360 \\
Coil current (I) & $25 \mathrm{~A}$ \\
Length (L) & $1343.5 \mathrm{~mm}$ \\
Polar surface width (W) & $28 \mathrm{~mm}$ \\
\hline
\end{tabular}

Define material properties. First we use Q235B as the material of track and electromagnet, and the flux density saturation of Q235B is about 1.4T. Then we can obtain the magnetization curve as shown in Fig. 2.

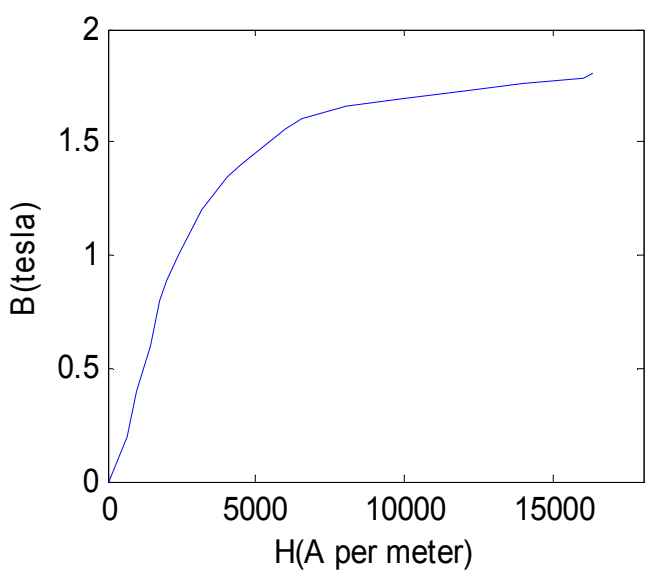

Fig. 2 Magnetization curve of Q235B

Mesh division. In the Ansoft software, mesh can be generated automatically according to the model structure.

Define boundary conditions. We set the automatically generated boundary of the software to "exclude", and redefine the small one with the boundary of the analytical model in the 3D electromagnetic field analysis.

Load the model. In order to complete the load, the total current intensity or the surface current density is applied during the static magnetic field analysis. 


\section{Calculation results and analysis}

Ups and downs with other four degrees of freedom. As the suspension air gap is $7 \mathrm{~mm}, 8 \mathrm{~mm}$, $9 \mathrm{~mm}$ respectively, the suspension electromagnetic force characteristics is shown in Fig. 3, when the movement of traverse, yaw, pitch or roll exist.
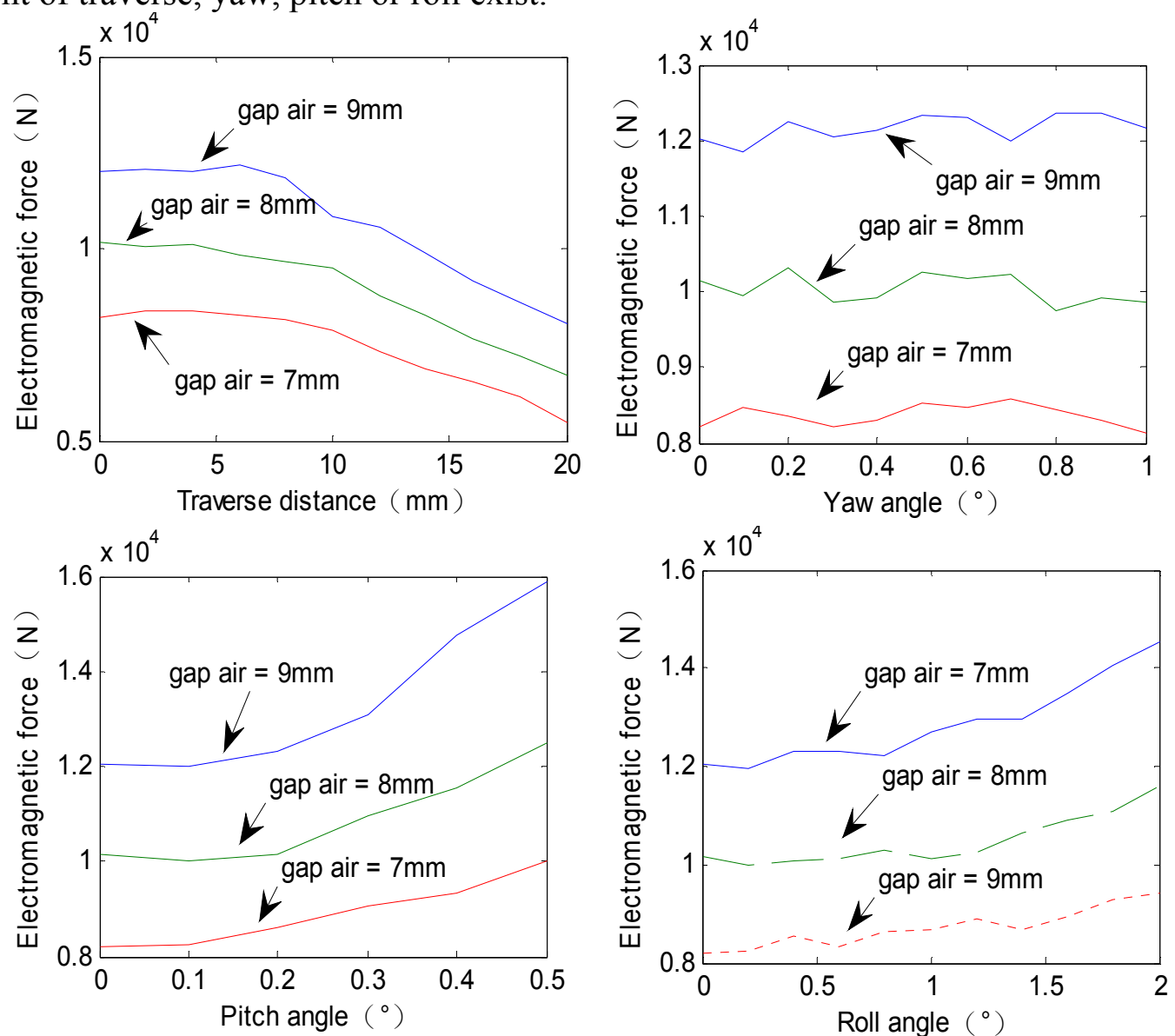

Fig. 3 Ups and downs with other four degrees of freedom

The Fig. 3 shows that in the same suspension air gap, the bigger the traverse distance is, the smaller the suspension electromagnetic force is, and the force increases with the increases of the pitch angle and roll angle, but the influence of yaw angle on the force is not large. For example, when the suspension air gap is $8 \mathrm{~mm}$, the suspension electromagnetic force reduces from $10156 \mathrm{~N}$ to $6686.3 \mathrm{~N}$ while the traverse distance changes from $0 \mathrm{~mm}$ to $20 \mathrm{~mm}$, the force decreases by $34.16 \%$, and the force increases from $10156 \mathrm{~N}$ to $12503 \mathrm{~N}$ while the pitch angle changes from $0^{\circ}$ to $0.5^{\circ}$, the force rises $23.1 \%$, moreover, the force increases from $10156 \mathrm{~N}$ to $11602 \mathrm{~N}$ while the roll angle changes from $0{ }^{\circ}$ to $2{ }^{\circ}$, the force rises $14.2 \%$. It shows from Fig. 3, four groups of curves are basically parallel, so there is no suspension electromagnetic force coupling between ups and downs and other four degrees of freedom.

Traverse with pitch or roll. As the suspension air gap is $8 \mathrm{~mm}$, the suspension electromagnetic force characteristics with the changes of traverse distance as shown in Fig. 4, when the movement of pitch or roll exist. 

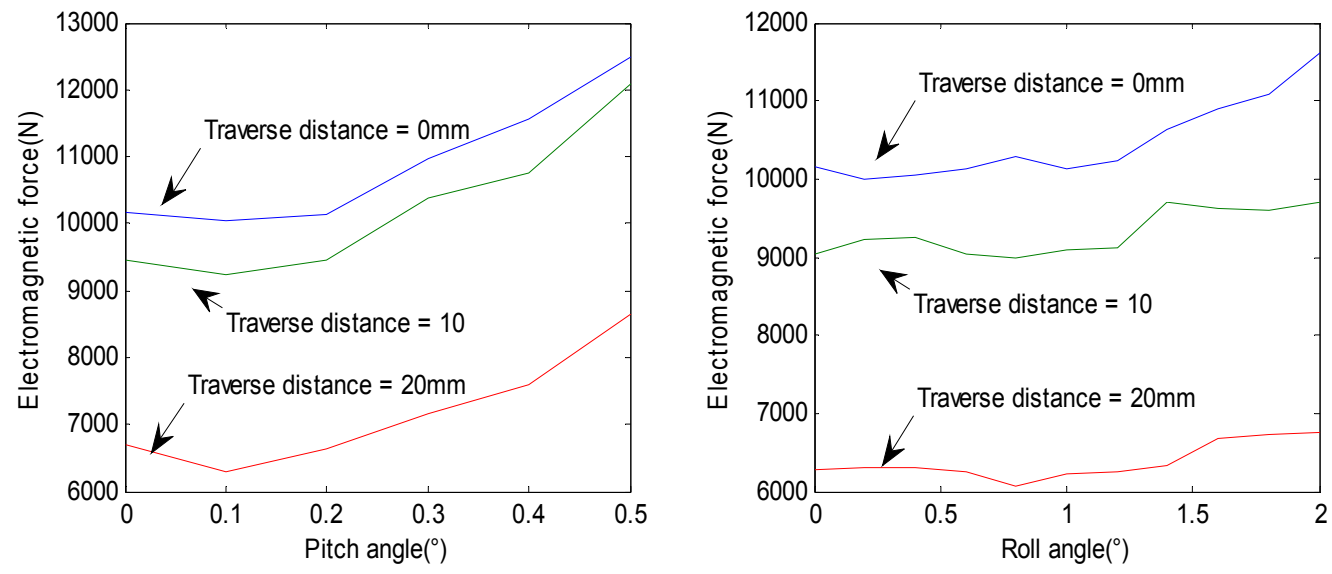

Fig. 4 Traverse with pitch or roll

As is shown in Fig. 4, in the same traverse distance, the bigger the pitch angle is, the bigger the suspension electromagnetic force is, and the force with the change of roll angle associated with the traverse distance. For example, when the traverse distance is $20 \mathrm{~mm}$, the force increases from 6686.3 $N$ to $8643.1 \mathrm{~N}$ while the pitch angle changes from $0^{\circ}$ to $0.5^{\circ}$, the force rises $29.26 \%$; When the traverse distance is $0 \mathrm{~mm}, 10 \mathrm{~mm}$ and $20 \mathrm{~mm}$ respectively, the force rises $14.2 \%, 7.5 \%$ and $7.76 \%$ respectively. Thus, it exist coupling of electromagnet between traverse and roll.

Pitch with roll. As the suspension gap is $8 \mathrm{~mm}$, the suspension electromagnetic force characteristics is shown in Fig. 5 when pitch and roll movement exist.

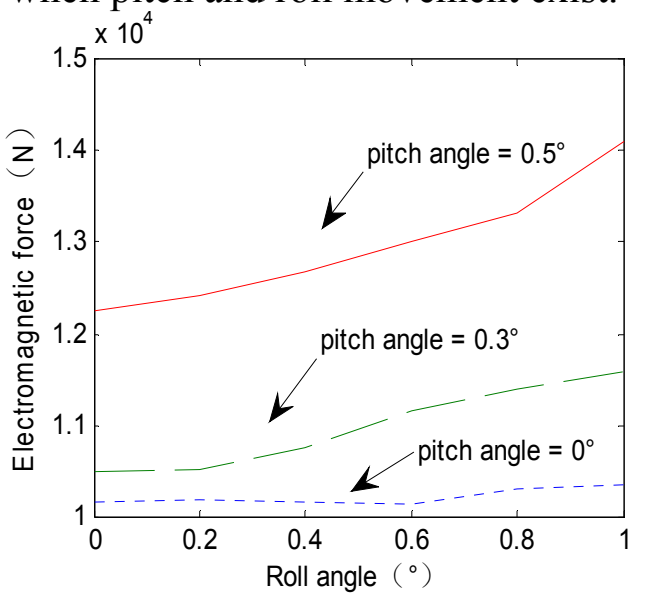

Fig. 5 Pitch with roll

As is shown in Fig. 5, when the pitch angle is certain, the force increases with the increases of the roll angle. For example, when the pitch angle is $0.5^{\circ}$, the force is increased from $12251 \mathrm{~N}$ to $14106 \mathrm{~N}$ while the roll angle changes from $0^{\circ}$ to $1^{\circ}$, the force rises $15.4 \%$. We can see from Fig. 5 , three curves is not parallel, and the bigger the pitch angle is, the bigger the growth of the force is. Thus, it exist coupling of suspension electromagnet between pitch and roll movement.

\section{Conclusion}

In the case of certain electromagnet parameters, the suspension electromagnetic force is not only influenced by suspension air gap. The traverse, pitch and roll movement also take big influence to the force, but the impact of yaw angle is not large. It creates a patent coupling to the suspension electromagnetic force, when traverse and roll movement or pitch and roll movement existed, that means it has big difference to only exist a single movement.

The analysis of the simulation in this paper laid the foundation to establish more accurate suspension electromagnetic force model, so it contributed to provide a more in line with the actual magnet-track model for maglev control technology research and dynamics research. 


\section{Acknowledgements}

This work is supported by the National Key Technology R\&D Program of the 12th Five-year Plan, Systematic Study on Engineering Integration of High Speed Maglev Transportation, 2103BAG19B01.

\section{References}

[1] W. Brzezina, Lan gerholc J,Lift and side force on rectangular pole pieces in two dimensions, Journal of Applied Physics. 1974.45(4) 1869-1872.

[2] Xie Yunde, Chang Wensen, Single electromagnet suspension electromagnetic force calculation and motion stability and controllability of electromagnetic type maglev train, Journal of the China Railway. 1995, 17 (1) $38-47$.

[3] Luo Fang, Zhang Kunlun, Numerical calculation and analysis of electromagnetic forces of U-shape suspension electromagnet for maglev vehicle, The locomotive electric transmission. 2002 (3) $32-34,39$.

[4] Luo Fang, Zhang Kunlun. Electromagnetic field analysis on suspension magnet of EMS maglev vehicle, Electric drive. 2002 (1) 27 - 28, 34.

[5] Liu Shaoke, Ni Hongyan, Zhang Kuikui. The Force Characteristic of Low Speed Maglev Train under Suspension Electromagnet Rolling, Study on the urban rail transit. 2007 (7) 22-25.

[6] Liu Shaoke, Ni Hongyan, Zhang Kuikui, Analysis on Guidance Ability for Speed Maglev Train , Electric drive locomotive. 2007 (2) 36-38.

[7] Ni Hongyan, Study on the electromagnetic characteristics of maglev suspension electromagnet at Mid and Low speed maglev, Changsha: National University of Defense Technology, 2005. 11.

[8] Zhang Kun. Maglev train suspension system of digital control technology research, Changsha: National University of Defense Technology, 2004. 10. 